\title{
The Tree of Wisdom: Maintaining epistemological health within an (emerging) evidence-free environment
}

\author{
Peter C Wyer MD \\ Associate Professor of Emergency Medicine, Columbia University Medical Center, New York, NY, USA
}

\begin{abstract}
Mounting concerns regarding the corruption of the clinical research enterprise by the pharmaceutical industry, as well as demonstrations of the inappropriateness of traditional research designs and consequent clinical guidelines to direct application to patient care, have led to challenges to the integrity of the evidence-based medicine (EBM) movement. However, the emerging crisis of confidence in clinical research should be seen as a threat to the viability of the entire healthcare system, not simply to EBM. Efforts of the EBM movement to represent itself as the brokers and mediators of the clinical research-healthcare interface are impediments to a full appreciation of the dilemma. Recognizing the implications of contrasting epistemological stances regarding the relationship of clinical research findings to healthcare policy and practice is essential to maximizing the value of research to the healthcare system. A synergy between empiricism-rationalism epistemologies, particularly conspicuous within the EBM movement, is identified as an important philosophical barrier to achievement of this goal. The notion of an evolutionary hierarchy of knowledge and wisdom is proposed as a vehicle to demonstrate a social constructivist alternative to a dualistic epistemology. Contrasting examples of social constructivist and empiricist-rationalist descriptions of integration of research with healthcare practice are provided for purposes of illustration.
\end{abstract}

\section{Keywords}

Clinical practice guidelines, CONSORT initiative, corruption in clinical research, epistemology, evidence-based medicine, GRADE system, hierarchies of evidence, knowledge, knowledge translation, patient factors, person-centered healthcare, philosophy of medicine, research-driven framework, shared decision-making, social processes, wisdom

\section{Correspondence address}

Dr Peter Wyer, Department of Emergency Medicine, Columbia University, 622 W $168^{\text {th }}$ Street, New York, NY 10032 , USA. E-mail: pw91@cumc.columbia.edu

Accepted for publication: 26 March 2018

The tree of wisdom is watered by tears. Swiss Proverb

\section{Introduction}

From weather forecasts to the results of national elections to the latest headlined research, we live in a time of major uncertainty. Fabricated information in the guise of electronically disseminated news reports has contributed to an environment in which factual assertions such as the annual calculation of the average global temperature seem challengeable. Former chairman and CEO of the Cable News Network Walter Isaacson recently suggested in an interview with CNN reporter Christiane Amanpour that the ability to "apply facts to received wisdom" may be undermined by the politicization of news and factual information [1].

The erosion of confidence in factual information within the social and political sphere has its parallel within healthcare. Driven by continued exposures of deceptive practices in clinical research, mounting skepticism regarding the credibility of trial results on effectiveness of medical therapeutics has generated a pileup of publications challenging the practical usability of clinical research [28]. Completing the parallelism to the aforementioned developments in the social and political sphere individual and commercial agendas drive many of the instances of falsification and misrepresentation of research reports. In one particularly egregious case, an investigative metaanalysis determined that published, manufacturer sponsored, trial reports on effectiveness of the antidepressant drug roboxetine had excluded up to $74 \%$ of eligible and enrolled patients from the published results [9]. When the data from these patients were incorporated into the analysis, the apparent benefit of the drug was eliminated $[9,10]$.

Fraud and misrepresentation by researchers and manufacturers are not the only challenges to the value of clinical research within the healthcare system. Boyd et al. [11] demonstrated that the framework of clinical trials, as it has emerged over the past half century, results in 
disease-specific clinical guidelines that are incapable of addressing the needs of patients with multiple health conditions. Such individuals have already become the most commonly encountered patients in many practice settings. Boyd et al. [11] showed that clinical guidelines passing current quality standards characteristically generate sets of recommendations that are impractical, if not outright dangerous. Other investigators have reported similar results [12]. Although attempts are underway on the part of guideline developers and methodologists to define ways of mitigating the dilemma [13], it may take decades for the clinical research enterprise to develop a body of research information that conforms to the reality of clinical practice.

In the face of such abuses and challenges, some authors have gone so far as to blame the evidence-based medicine (EBM) movement for contributing to the consequent dilemma and to claim that EBM is a movement in crisis $[2,3]$. The plausibility of such arguments is dependent on one's preferred definition of EBM. Previous commentaries have proposed that the term EBM should be used to refer to the medical education initiative that was launched in 1992 in the pages of the Journal of the American Medical Association [14]. The principal focus of the initiative was to increase research literacy among clinical practitioners, thereby empowering them to exercise their own critical judgment in the application of information from research to healthcare decision-making $[15,16]$. By this non-inflated definition of EBM, the latter is not culpable for the extremes to which researchers and manufacturer sponsors of clinical research have gone in recent years to maximize academic currency and product sales. Indeed, the EBM movement has made valuable contributions to immunizing consumers of research against the discoverable aspects of manufacturer and researcher subterfuge [17], even if literacy education remains powerless against non-easilydiscoverable misrepresentation.

An alternative, expanded, definition of EBM, uses the term to denote virtually the entire interface between the clinical research enterprise and the healthcare system $[4,18]$. Within this minimally bounded vision of EBM, which, depending upon one's predilections might be called either "Everything Bad in Medicine" or "Everything Better in Medicine", commentators have held EBM responsible for the breakdown in integrity of research information $[15,19]$. The latter perspective consistently leads to unfocused discussions about the problems of the healthcare system [16]. It also impedes the ability to focus upon the epistemological controversies in which narrowly defined EBM has played a central role and which are the focus of the current paper.

\section{Not a Crisis in "EBM"}

It is important to be clear on one crucial point. Although, as mentioned, EBM as originally framed in 1992 [14], as a result of overreach in its formulation, has served as the center of an important epistemological debate [20], it has done so not primarily because of the actual content of the initiative, but because the debate itself corresponds to much deeper issues that have prevailed within the healthcare arena both before and since. It is these issues, which center on the importance and role of fact in shaping healthcare policy and practice, that are thrown into crisis at the point that confidence in the empirical domain of relevant fact is threatened. Historically, two factors have contributed to the perception of EBM as an amorphous "meta-entity", confounding attempts to locate it within a coherent epistemological critique. Firstly, the term “evidence-based” itself was immediately recognized as a compelling marketing and branding label for healthcare initiatives and products emerging in the 1990's. This aspect was well described by David Eddy, who had himself earlier coined the phrase to describe a research oriented approach to development of clinical guidelines [21].

The second factor that lent EBM its 'larger than life' countenance was its tendency to over-reach. Over the years, EBM as a brand served as the basis of the careers of a number of individuals who ultimately became highly prominent as a result. It has appeared to serve the interests of such individuals to list things as 'accomplishments of EBM', such as the CONSORT initiative [22] and the original impetus behind evidence-based clinical guidelines [23], that were achieved by individuals who had no affiliation or identification whatever with the EBM movement $[4,18]$. It is within the resulting context that the boundaries between EBM, the use of clinical research in healthcare and the research enterprise itself, have become blurred in the literature [15] and that others have claimed to perceive a 'crisis in EBM' [3]. However, the actual crisis being spawned by the declining confidence in the integrity of clinical research is much better understood as one of the healthcare system itself and its ability to validly "apply facts to received knowledge and wisdom". To call it a "crisis in EBM" is merely to propagate the excesses and over-reaches of that movement.

One set of authors with ties to the British Medical Journal (BMJ), but not otherwise connected to the EBM movement, seems to have recognized that the crisis of confidence in research is external to EBM in its origins, even though their article implies that EBM is a principal casualty of that crisis [5]. Their prescriptions for remedying the corruption of clinical research are reasonable in themselves. However, many of them, such as strengthening drug and device regulation, may be considered to already have been shown to have failed. Others, such as "increasing the systematic use of existing evidence", are poorly elaborated in the "manifesto" document [5] and also seem to beg the question of the undermining of confidence. What neither the BMJ authors nor those from the EBM movement itself appear to recognize is that the erosion of believability of verifiable facts from research generates a crisis within healthcare of a nature that must be referred to the domain of epistemology. While regulatory 'fixes' may be transiently useful, a viable remedy must ultimately be framed from within that domain. 


\section{The Epistemological Riddle}

As already suggested, EBM was not the cause of the current crisis in confidence in clinical research and should not itself be considered to be its principal casualty. Additionally, EBM is not a convincing candidate to provide a resolution for the crisis. Firstly, the tools of critical appraisal of published clinical research developed at McMaster University Canada [14] are inherently incapable of uncovering the kind of subterfuge reflected in the roboxetine affair [9]. More challenging still are the dilemmas posed by patient multi-morbidity and the failure of clinicians to follow even the most rigorously developed clinical guidelines [24-26]. These likely require approaches that reflect an epistemology that is qualitatively beyond that of the EBM movement. Loughlin et al. [27] recently commented on an interesting solution to a dilemma that resulted when an author in search of a new medical discipline was confronted by contradictions inherent in an empiricist ideology [28]. The author in question posed a rationalist solution to the conundrum. I suggest that this constituted an example of a more general phenomenon. Specifically, when empiricism, particularly the extreme form known as positivism, runs up against an impasse, it magically transforms itself into its polar opposite, rationalism, and devises a structured formulaic solution to the dilemma.

For example, trial reports and systematic reviews that pool together the results of individual trials for the purpose of securing the most precise estimates of effect possible for specific outcomes, sometimes present those results with a minimum of interpretation. Indeed, editors of major journals often discourage investigators from making unequivocal recommendations based upon their results, no matter how strong. A possible consequence of letting results of research 'speak for themselves' is the observed fact that training in critical appraisal and other aspects of teaching use of research reports for problem solving purposes, over several decades, has had no measurable impact on clinical practice [29,30]. Faced with such findings, a characteristic response from the empiricist camp is to construct ornate formulations of recommendations for practice such as "evidence-based" clinical guidelines. Structured step-wise algorithmic formulas for practice are highly suggestive of a rationalistic approach to problem solving in which prefixed abstract formulas are substituted for improvised and tailored navigation of empirical challenges. In other words, rationalism serves as a 'bailout' for a positivist philosophical stance at the point that the latter fails to deliver observed fact in a form that allows its translation into knowledge and knowledge into wisdom. It should be emphasized that this tendency is quite ubiquitous within the healthcare system in its troubled relationship to the world of research. The issues around the EBM movement are useful as examples that illustrate the overall dilemma.

Returning to the relationship between corruption of factual information from clinical research and the potential starvation of knowledge and wisdom that may result from it, it is necessary to define an understanding of the interrelationship between these complex domains. Doing so in an explicit fashion allows meaningful discussion of the relationship between clinical research and healthcare. Figure 1 illustrates an admittedly over-simplified conceptual model of the relationship between data, information and knowledge and between all of these and the domain of wisdom. The relationship is characterized by each successive stage in the escalation subsuming the content of all of the prior stages. Hence, quantitative data points, such as recorded for each human subject in the course of a clinical trial, are carried into the succeeding phase of information through a process of analysis based upon pattern recognition, prior hypothesis and consequent interpretation. Similarly, the interpreted results of studies, that is, information, are brought to bear on the domain of knowledge, within which a much more complex process integrates and socially constructs "justified true belief", to use a classic aphorism. Hovering above the whole and drawing nourishment from all of the phases of the prior escalation, is the tree of wisdom within which the successes and failures of prior knowledge are adjudicated and determinations of things such as social justice and transformative actions are made. Clearly, if data are falsified or corrupted through erroneous selection, information is transformed into the equivalent of "fake news" and the belief upon which knowledge depends is no longer justified. Under such circumstances, the tree of wisdom withers and dies. If we take the content of Figure 1 as an organic whole, it can be seen as a prototype of what we might call an 'evolutionary hierarchy'. This requires some explanation which I will briefly provide before concluding with some illustrative examples.

\section{Figure 1 The evolutionary escalation of successively nested domains feeding knowledge and wisdom, respectively. Each successive domain subsumes the entire content of those that are lower in the hierarchy. The domain of wisdom embodies the full process and reciprocally cross nourishes it}

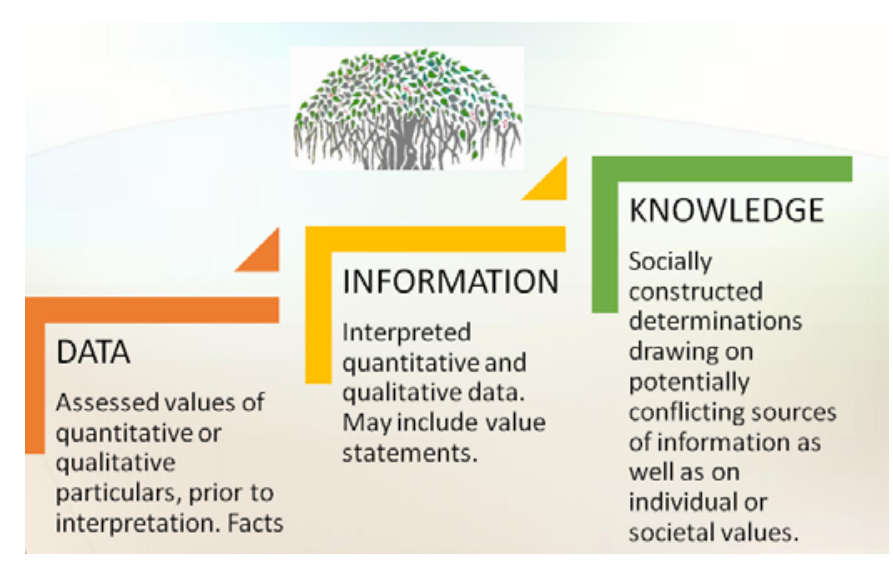




\section{A Hierarchy of Hierarchies}

The term 'hierarchy' has suffered abuse and misuse in the course of debates over EBM ideology in the past several decades. However, it corresponds to a concept that is quite crucial to a discussion of the interplay between research findings and healthcare policy and practice. Hence, we need clarification regarding its use. Firstly, the term has several accepted usages. For example, 'hierarchy' may refer to an arbitrary ranking among elements, such as an 'organizational' or 'political' hierarchy. Hence, a King may be an idiot, but nonetheless secure in his position as Head of State at the top of a regal hierarchy by virtue of his blood line. On the other hand, one may speak of a 'conceptual hierarchy' in which an underlying ordering principle is at play. In the case of the 'hierarchy of evidence', notoriously advanced early on in the course of the EBM movement [31,32], such an ordering principle was based on perceived susceptibilities to bias, or threats to 'internal validity', embedded in particular clinical research designs. Within this scheme, appropriately concealed randomization, which, assuming a sufficiently large study population, maximizes the likelihood that confounders of the estimates of effect, known and unknown, will be equally distributed across the study groups belongs at the top. Designs involving greater implicit susceptibilities to such confounding are positioned at lower levels.

The design-based conceptual hierarchy of evidence posed by EBM advocates in the 1990's, although not without its opponents [33], served as a commonly encountered element in discussions of clinical research evidence in relationship to clinical guidelines, as well as in other contexts. Less commonly appreciated, but perhaps even more important, was the conceptual hierarchy of knowledge posited at the dawn of the EBM movement itself. The index publication of EBM of 1992 [14] proposed a hierarchy of medical knowledge in which evidence from research occupied the upper rung followed by pathophysiological knowledge and then by knowledge based on clinical experience [34]. For some, this hierarchical re-ordering of the basis of healthcare knowledge triggered the longstanding controversy and push-back against the EBM movement [35]. They, at least intuitively, recognized the pitfalls of the radical empiricist, or positivist, commitment of that movement which the ordering principle embedded in the EBM hierarchy of knowledge reflected. The proposed scheme prescribed that easily verifiable or refutable facts (clinical research evidence) were to be placed at the top, followed by more complex inferences born of empirical observations of biological and physiological systems in health and disease (pathophysiological knowledge). At the very bottom came empirically unverifiable (from a positivist standpoint) inferences generated by the complex domain of clinical practice. The latter are comprised of the experience of a clinician informed by years of training admixed with the inputs of individual patients, their ailments and life stories. Contemporary critics intuited that, from a social constructivist perspective, the positivist re-ordering of informants of clinical decision-making needed to be turned on its head (or perhaps restored to the original position), with the social and relational processes that ideally generate healthcare decisions at the top and information from clinical research at the bottom [35]. Over time, discerning observers of the ensuing process began to catch up to the early critics [34].

The foregoing summary describes in pure form two distinct conceptual hierarchies, one pertaining to research evidence and the other of knowledge related to clinical decision-making. They were occasionally posited by the EBM movement in that form. More commonly, however, they were mixed together in a much more confusing fashion as a kind of chimera in which research designs such as randomization were admixed with knowledge elements such as 'clinical expertise' or 'opinion'. Such formulations abound in recent editions of standard EBM textbooks [36-38]. A recent summary of the accomplishments of the EBM movement [18] lists "clinical expertise" at the very bottom of a 'hierarchy' that commences with randomized trials.

Summarizing the presentation of a 'hierarchy of hierarchies', we have, in ascending degree of usefulness to the issue at hand, hierarchy as an arbitrary ranking of related elements, as a conceptual ordering of related elements and as an evolutionary escalation of increasingly complex forms within a domain. Of these, the latter, such as illustrated in Figure 1, is compatible with a social constructivist epistemological framework and allows an escape from the dualistic empiricist-rationalist conundrum.

\section{Illustrative Examples}

Two examples illustrate the contrast between a rationalistic solution to the perceived inadequate use of research in healthcare and an approach reflecting social constructivist principles. They will be described only briefly here. The first can be seen as an extreme example of an attempted rationalist solution to the failure of a radical empiricist educational movement to increase uptake of research in clinical practice. EBM, as a medical education intervention, has had substantial impact on curricula at both undergraduate and graduate levels. EBM skills have been widely incorporated into the competency-based curricular frameworks of medical education throughout North America and Europe. However, after almost three decades since the initiative was announced [14], it remains impossible to demonstrate that the teaching of EBM skills to physicians in training has had any impact on clinical practice $[29,30]$. Faced with this reality and with other compelling evidence [39], many, if not most, of the surviving founders of the EBM movement have turned their efforts in the direction of development and implementation of clinical guidelines. The Grading of Recommendations, Assessment, Development and Evaluation (GRADE) project, which started as an initiative to reform and upgrade earlier systems for grading healthcare recommendations in clinical guidelines [40], has more recently ballooned into an effort to encompass the entire process of development and implementation of guidelines within all levels of the healthcare system. 
The GRADE approach to evaluating the quality of research supporting the choice of interventions in specific settings of disease and prevention goes beyond the simplistic design-based hierarchies that characterized guideline development in the 1980's and 1990's and will not be reviewed in detail here [41]. More relevant is how the project is being expanded in an attempt to encompass all of the social processes involved in healthcare decisionmaking within a formulaic and algorithmic framework. The "evidence to decision" framework involves navigation of a checklist of over one hundred and forty items aimed at guiding the process that leads from the finished tables of evidence pertaining to particular therapeutic options and desired outcomes to the formulation of recommendations regarding practice and policy [42]. Perhaps most telling is the term "evidence to decision", which subtly suggests that the social processes that lead to healthcare actions and choices are shaped consequent to the findings of research rather than by the needs and exigencies of patient and practitioner problems and concerns.

Another feature of the GRADE system also supports the foregoing perception. In the course of defining how strong versus weak recommendations are to be interpreted, GRADE prescribes that in the former case, when the recommendations are 'strong', which almost always means that the research evidence is 'strong', practitioners should simply 'tell the patient what to do'. However, in the second case, when the recommendations are sufficiently 'weak', which once again almost always points to weak or equivocal research evidence, the practitioner may consider invoking shared decision-making [43]. GRADE also suggests that 'strong' recommendations, as opposed to 'weak' recommendations, be used as quality indicators for healthcare policy enforcement. Although the GRADE system allows for criteria other than clinical research evidence, such as patient values and preferences, resource availability and cost, as a framework largely crafted by epidemiologists and methodologists it can be seen as an attempt to subsume the social processes involved at all levels of decision-making into a research driven framework.

Multiple studies and analyses have been devoted to the issue of practitioner adherence to practice guidelines and the lack thereof [25]. Similarly, studies have attempted to assess guideline adherence through such means as audits of patient care using national registries [39] and changes in clinical parameters in the presence and absence of specific guideline implementation efforts [44] and have largely yielded negative or only marginally positive results. An interesting series of ethnographic investigations has raised the question of whether fidelity to guidelines is being assessed in the right way [45]. It also provides an example of what use of clinical research and guidelines may look like in a socially healthy practice setting. Gabbay and Le May [45] used qualitative research methods in two clinic settings in the UK, one community and one universitybased, for the purpose of studying how practitioners use and share research information in their day to day practice. They selected the study sites as clinics constituting the highest quality practices in their regions and which had won numerous awards and citations for excellent quality of care [46].

The investigators found that both clinics maintained a vibrant culture of social interaction characterized by regular meetings involve all of the professional staff as well as frequent informal conversations. In the course of these interactions, problematical cases were discussed as well as other practice issues. In that context, current guidelines were mentioned from time to time. The practitioners who were interviewed espoused familiarity with guidelines through their professional journals and other materials. However, at no time did the investigators observe practitioners undertaking formal direct access to research or even to clinical guidelines, despite the fact that electronic access to such was readily available. Rather, such information entered into the socially constructed framework that Gabbay and Le May came to call "mindlines", a construct that they consider to be analogous in a social context of what have been called "illness scripts" within the context of individual practitioner cognition [47]. Gabbay and Le May provide a window on a very different world of dialogue and concerted actions from that of the highly regimented environment suggested by GRADE. Although we don't know how the clinics they studied would have fared in the published assessments of guideline use, what we do know is that the health professionals within them believed themselves to be adequately informed by such instruments and by the information included therein.

\section{Conclusion}

If the policies, practices and social processes that define healthcare in today's Society reflect the collective wisdom of the culture in which they are embedded, then research of all kinds must provide nourishment and renewal to that wisdom. To further draw upon our metaphor, just as important as the nourishment that the tree receives is that which the tree, directly and indirectly, gives back to the soil. Nonetheless, an evolutionary hierarchy is evident; the tree cannot be derived from the soil through a simple step by step formula. Similarly, within healthcare, facts derived from the outcomes of clinical research cannot themselves generate practice, either singly or through attempts to reduce the wisdom of practice to fact. But, if the factual soil is contaminated or falsified, healthcare itself will ultimately degenerate to mindless obeisance to tradition.

Detoxification of the clinical research environment, once contaminated, is challenging. Processes extending from outside the healthcare system will likely be required to remedy subterfuge and misrepresentation of research findings for gain. As for challenges such as multimorbidities that go to the heart of research design, it is the soil that needs to be enriched by the fruit of the tree. For example, researchers and guideline developers need to pay much more attention to the perceived needs for information and guidance on the part of practitioners and systems of healthcare delivery than they have heretofore. The movement to involve patient and practitioner 
stakeholders in research and guideline efforts is proceeding well internationally and in the right direction. However, the point of entrance of stakeholders into the research and policy arena is still relatively downstream from the point of origin of such efforts. The gaps will remain refractory to the creativity of researchers and the complex algorithms of rationalist guideline efforts until the relevant social processes can be brought into a closer approximation to the kind of communities of practice described by Gabbay and Le May.

\section{Acknowledgements and Conflicts of Interest}

This article expands upon a presentation delivered at the Fourth Annual Conference and Awards Ceremony of the European Society for Person Centered Healthcare, 26-27 October 2017 in Westminster, London, UK. The author acknowledges Professor Michael Loughlin for his helpful comments and suggestions. There are no conflicts of interest to declare.

\section{References}

[1] Isaacson, W. (2018). Leonardo da Vinci. Interview with Christiane Amanpour on PBS 12 January 2018. Available at: http://www.pbs.org/video/amanpour-deanbaquet-and-walter-isaacson-yhgy4a/. Accessed 15 March 2018.

[2] Every-Palmer, S. \& Howick, J. (2014). How evidencebased medicine is failing due to biased trials and selective publication. Journal of Evaluation in Clinical Practice 20 (6) 908-914.

[3] Greenhalgh, T., Howick, J., Maskrey, N. \& Evidence Based Medicine Renaissance Group. (2014). Evidence based medicine: a movement in crisis? British Medical Journal 348 (g3725) 1-7.

[4] Greenhalgh, T., Snow, R., Ryan, S., Rees, S. \& Salisbury, H. (2015). Six 'biases' against patients and carers in evidence-based medicine. BioMed Central Medicine 13 (1) 200.

[5] Heneghan, C., Mahtani, K. R., Goldacre, B., Godlee, F., Macdonald, H. \& Jarvies, D. (2017). Evidence based medicine manifesto for better healthcare: A response to systematic bias, wastage, error and fraud in research underpinning patient care. Evidence Based Medicine 22 (4) 120-122.

[6] Ioannidis, J.P.A. (2008). Effectiveness of antidepressants: an evidence myth constructed from a thousand randomized trials? Philosophy, Ethics, and Humanities in Medicine 3, 14.

[7] Ioannidis, J.P.A. (2016). Evidence-based medicine has been hijacked: a report to David Sackett. Journal of Clinical Epidemiology 73, 82-86.

[8] Ross, J.S., Hill, K.P., Egilman, D.S. \& Krumholz, H.M. (2008). Guest Authorship and Ghostwriting in Publications Related to Rofecoxib: A Case Study of Industry
Documents From Rofecoxib Litigation. Journal of the American Medical Association 299 (15) 1800-1812.

[9] Eyding, D., Lelgemann, M., Grouven, U., Härter, M., Kromp, M., Kaiser, T., Kerekes, M. F., Gerken, M. \& Wieseler, B. (2010). Reboxetine for acute treatment of major depression: systematic review and meta-analysis of published and unpublished placebo and selective serotonin reuptake inhibitor controlled trials. British Medical Journal 341, c4737.

[10] Groves, T. (2010). Evidence debased medicine (Editorial). British Medical Journal 341, c5715.

[11] Boyd, C.M., Darer, J., Boult, C., Fried, L.P., Boult, L. \& Wu, A.W. (2005). Clinical practice guidelines and quality of care for older patients with multiple comorbid diseases: implications for pay for performance. Journal of the American Medical Association 294 (6) 716-724.

[12] Muth, C., Kirchner, H., van den Akker, M., Scherer, M. \& Glasziou, P.P. (2014). Current guidelines poorly address multimorbidity: pilot of the interaction matrix method. Journal of Clinical Epidemiology 67, 1242-1250.

[13] Uhlig, K., Leff, B., Kent, D., Dy, S., Brunnhuber, K., Burgers, J.S., Greenfield, S., Guyatt, G., High, K., Leipzig, R., Mulrow, C., Schmader, K., Schnemann, H., Walter, L.C., Woodcock, J. \& Boyd, C.M. (2014). A framework for crafting clinical practice guidelines that are relevant to the care and management of people with multimorbidity. Journal of General Internal Medicine 29 (4) 670-679.

[14] Evidence-Based Medicine Working Group. (1992). Evidence-based medicine: A new approach to teaching the practice of medicine. Journal of the American Medical Association 268, 2420-2425.

[15] Wyer, P. \& da Silva, S.A. (2015). 'One mission accomplished, more important ones remain': commentary on Every-Palmer, S. \& Howick, J. (2014). How evidencebased medicine is failing due to biased trials and selective publication. Journal of Evaluation in Clinical Practice 20 (6) 908-914. Journal of Evaluation in Clinical Practice 21 (3) 518-528.

[16] Wyer, P. \& Silva, S.A. (2015). 'All the King's horses . . .': the problematical fate of born-again evidence-based medicine: commentary on Greenhalgh, T., Snow, R., Ryan, S., Rees, S. \& Salisbury, H. (2015). Six 'biases' against patients and carers in evidence-based medicine. BioMed Central Medicine 13, 200. Journal of Evaluation in Clinical Practice 21 (6) E1-E10.

[17] Montori, V.M., Jaeschke, R., Schunemann, H.J., Bhandari, M., Brozek, J.L., Devereaux, P.J. \& Guyatt, G.H. (2004). Users' guide to detecting misleading claims in clinical research reports. British Medical Journal 329 (7474) 1093-1096.

[18] Djulbegovic, B. \& Guyatt, G.H. (2017). Progress in evidence-based medicine: a quarter century on. Lancet 390, 415-423.

[19] Wyer, P.C. \& Silva, S.A. (2013). Tarnished Gold: The Sickness of Evidence-based Medicine by Steve Hickey and Hilary Roberts: EBM as an Avatar of Modern Medicine. European Journal for Person Centered Healthcare 1, 8087.

[20] Tonelli, M.R. (1998) The philosophical limits of evidence-based medicine. Academic Medicine 73, 12341240 . 
[21] Eddy, D.M. (2005). Evidence-based medicine: A unified approach. Health Affairs 24, 9-17.

[22] Moher, D., Schulz, K.F., Altman, D.G. \& Lapage, L. (2001). The CONSORT statement: revised recommendations for improving the quality of reports of parallel-group randomised trials. Lancet 357, 1191-1194.

[23] Eddy, D.M. (1990). Practice Policies: Where Do They Come From? Journal of the American Medical Association 263, 1265-1275.

[24] Barnett, M.L. \& Lindner, J.A. (2014). Antibiotic Prescribing for Adults With Acute Bronchitis in the United States, 1996-2010. Journal of the American Medical Association 311, 2020-2022.

[25] Cabana, M.D., Rand, C.S., Powe, N.R., Wu, A.W., Wilson, M.H., Abboud, P.C. \& Rubin, H.R. (1999). Why don't physicians follow clinical practice guidelines? A framework for improvement. Journal of the American Medical Association 282, 1458-1465.

[26] Perez , X., Wisnivesky, J.P., Lurslurchachai, L., Kleinman, L.C. \& Kronish, I.M. (2012). Barriers to adherence to COPD guidelines among primary care providers. Respiratory Medicine 106, 374-381.

[27] Loughlin, M., Wyer, P. \& Tanenbaum, S.J. (2016). Teaching by (bad) example: what a confused attempt to "advance" EBM reveals about its underlying problems: commentary on Jenicek, M. (2015). Do we need another discipline in medicine? From epidemiology and evidencebased medicine to cognitive medicine and medical thinking. Journal of Evaluation in Clinical Practice 21, 1028-1034. Journal of Evaluation in Clinical Practice 22, 628-633.

[28] Jenicek, M. (2015). Do we need another discipline in medicine? From epidemiology and evidence-based medicine to cognitive medicine and medical thinking. Journal of Evaluation in Clinical Practice 21 (6) 10281034.

[29] Ahmadi, S., Baradaran, H.R. \& Ahmadi, E. (2015). Effectiveness of teaching evidence-based medicine to undergraduate medical students: A BEME systematic review. Medical Teacher 37, 21-30.

[30] Coomarasamy, A. \& Khan, K.S. (2004). What is the evidence that postgraduate teaching in evidence based medicine changes anything? A systematic review. British Medical Journal 329, 1017-1021.

[31] Guyatt, G.H., Sackett, D.L., Sinclair, J.C., Hayward, R., Cook, D.J., Cook, R.J., for the Evidence-Based Medicine Working Group. (1995). Users' Guides to the Medical Literature. IX. A Methord for Grading Health Care Recommendations. Journal of the American Medical Association 274, 1800-1804.

[32] Levine, M., Walter, S., Haines, T., Holbrook, A., Moyer, V., for the Evidence-Based Medicine Working Group. (1994). Users' Guides to the Medical Literature. IV. How to Use an Article About Harm. Journal of the American Medical Association 271, 1615-1619.

[33] Feinstein, A.R. \& Horwitz, R.I. (1997). Problems in the "Evidence" of "Evidence-based Medicine". American Journal of Medicine 103, 529-535.

[34] Silva, S.A. \& Wyer, P.C. (2009). Where is the wisdom? II - Evidence-based medicine and the epistemological crisis in clinical medicine. Exposition and commentary on Djulbegovic, B., Guyatt, G.H. \& Ashcroft, R.E. (2009). Cancer Control 16, 158-168. Journal of Evaluation in Clinical Practice 15, 899-906.

[35] Tanenbaum, S.J. (1993). What Physicians Know. New England Journal of Medicine 329, 1268-1271.

[36] Greenhalgh, T. \& Buckingham, J. (2010). Searching the Literature. In: How to Read a Paper (4th Edn) (T. Greenhalgh, Ed.), pp. 15-30. Oxford: Wiley-Blackwell.

[37] Guyatt, G., Jaeschke, R., Wilson, M.C., Montori, V.M. \& Richardson, W.S. (2015). What Is Evidence-Based Medicine? In: Users' Guides to the Medical Literature: A Manual for Evidence-Based Clinical Practice (3rd Edn) (G. Guyatt, D. Rennie, M.O. Meade \& D.J. Cook Eds.), pp. 114. New York: McGraw-Hill.

[38] Straus, S.E., Glasziou, P. \& Richardson, W.S. \& Haynes, R.B. (2011). Therapy. In Evidence-Based Medicine (4th Edition) (S.E. Straus, P. Glasziou, W.S.Richardson \& R.B. Haynes Eds.), pp. 67-136. Oxford: Churchill Livingstone.

[39] McGlynn, E.A., Asch, S.M., Adams, J., Keesey, J., Hicks, J., DeCristofaro, A. \& Kerr, E.A. (2003). The quality of health care delivered to adults in the United States. New England Journal of Medicine 348, 2635-2645.

[40] GRADE Working Group. (2004). Grading quality of evidence and strength of recommendations. British Medical Journal 328, 1490-1494.

[41] Guyatt, G.H., Oxman, A.D., Kunz, R., Vist, G.E., Falck-Ytter, Y. \& Schunemann, H.J. (2008). What is "quality of evidence" and why is it important to clinicians? British Medical Journal 336, 995-998.

[42] Schünemann, H.J., Wiercioch, W., Etxeandia, I. et al. (2014) Guidelines 2.0: systematic development of a comprehensive checklist for a successful guideline enterprise. Canadian Medical Association Journal 186 (3) E123-E142.

[43] Andrews, J., Guyatt, G., Oxman, A. D. et al. (2013). GRADE guidelines: 14. Going from evidence to recommendations: the significance and presentation of recommendations. Journal of Clinical Epidemiology 66, 719-725.

[44] Worrall, G., Chaulk, P. \& Freake, D. (1997). The effects of clinical practice guidelines on patient outcomes in primary care: a systematic review. Canadian Medical Association Journal 156 (12) 1705-1712.

[45] Gabbay, J. \& Le May, A. (2004). Evidence based guidelines or collectively constructed "mindlines?" Ethnographic study of knowledge management in primary care. British Medical Journal 329, 1-5.

[46] Gabbay, J. \& Le May, A. (2011). Practice-Based Evidence for Healthcare: Clinical Mindlines. Oxon, UK: Routledge.

[47] Charlin, B., Tardif, J. \& Boshuizen, H.P.A. (2000). Scripts and Medical Diagnostic Knowledge: Theory and Applications for Clinical Reasoning Instruction and Research. Academic Medicine 75, 182-190. 